\title{
ESTRATÉGIAS DE REABILITAÇÃO EM AMBIENTE CARCERÁRIO: UMA DISCUSSÃO SOBRE SEGURANÇA PÚBLICA
}

\author{
Higor Serra Flores ${ }^{1}$ \\ Diego Canabarro Pires ${ }^{2}$ \\ Mateus Crauss ${ }^{3}$ \\ Vinicius Machado Gomes 4 \\ Alexandre Souza Silveira ${ }^{5}$ \\ Filipe dos Santos Moro ${ }^{6}$
}

RESUMO: É comum diferentes veículos de mídia noticiarem diariamente casos de violência, que refletem índices de criminalidade cada vez mais altos no país, escancarando graves problemas de segurança pública e também transmitindo uma sensação de insegurança na população. Deste modo, se tornam também mais recorrentes as discussões de como criar estratégias para a diminuição destes preocupantes fatores; existem discursos variados nesse sentido, sendo que muitos colocam a maior repressão como uma alternativa, e outros enfatizam que as mudanças precisam ser mais profundas, reduzindo os abismos sociais e as desigualdades, como uma forma de pensar a segurança pública a médio e longo prazo. Na conjuntura destas estratégias mais amplas, não se pode deixar de lado a discussão acerca do sistema prisional brasileiro, que se mostra desestruturada e em desconformidade com preceitos constitucionais. Esse debate é importante, na medida em que a reabilitação de detentos, é uma ação relevante na busca da redução de índices de criminalidade. A partir disso, o estudo tem como objetivo analisar ${ }_{100}$ importância da reestruturação do sistema prisional brasileiro, como objetivos específicos: analisar o atual panorama do sistema carcerário brasileiro, entender a função social e punitiva das prisões, analisar as consequências positivas dessa ideia de reformulação. O estudo se justifica a partir da ideia de que o sistema prisional brasileiro se encontra completamente desestruturado, não cumprindo suas funções em conformidade com preceitos centrais da Constituição, como da dignidade e dos direitos humanos, além do Estado não garantir estratégias eficazes em relação a reabilitação dos detentos, visando mitigar os índices de reincidência criminal. Para alcançar os objetivos propostos, a pesquisa é fundamentada por meio de uma revisão de literatura, com caráter qualitativo, em pesquisas

\footnotetext{
I formado em Administração de empresas. Universidade do norte do Paraná - UNOPAR EAD Santa Maria - RS e-mail: higor-flores@susepe.rs.gov.br

${ }^{2}$ Formado em engenharia Mecânica - Universidade federal de Santa Maria - RS e-mail - diego-

pires@susepe.rs.gov.br

3 formado em Direito - Universidade Franciscana de SANTA MARIA - RS e-mail: mateus-

crauss@susepe.rs.gov.br

4 formado em administração de empresas - Universidade do norte do Paraná - UNOPAR EAD - CACEQUI -

RS.e-mail: vinicius-gomes@susepe.rs.gov.br

5 formado em administração habilitação em empresas - FUNDAÇÃO UNIVERSIDADE FEDERAL DE RIO

GRANDE - RS.e-mail: alexandre@susepe.rs.gov.br

${ }^{6}$ formado em Direito - faculdade metodista de Santa Maria - RS.e-mail: filipe-moro@susepe.rs.gov.br
} 
relacionadas a segurança pública, de entendimento das funções do sistema prisional, e de possíveis estratégias para resolver os diversos problemas observados nesse ambiente.

Palavras-chave: Segurança pública. Prisões. Reabilitação. Estratégias.

\section{INTRODUÇÃO}

A segurança pública se trata de um segmento basilar para a efetivação de uma sociedade harmoniosa, além de ser uma premissa constitucional, que deve ser assegurada a todos os cidadãos, e que deve ser efetivada por meio de ações do Estado, usando diferentes estratégias e forças policiais.

É comum diferentes veículos de mídia noticiarem diariamente casos de violência, que refletem índices de criminalidade cada vez mais altos no país, escancarando graves problemas de segurança pública e também transmitindo uma sensação de insegurança na população. Deste modo, se tornam também mais recorrentes as discussões de como criar estratégias para a diminuição destes preocupantes fatores; existem discursos variados nesse sentido, sendo que muitos colocam a maior repressão como uma alternativa, e outros enfatizam que as mudanças precisam ser mais profundas, reduzindo os abismos sociais e as desigualdades, como uma forma 1008 de pensar a segurança pública a médio e longo prazo.

$\mathrm{Na}$ conjuntura destas estratégias mais amplas, não se pode deixar de lado a discussão acerca do sistema prisional brasileiro, que se mostra desestruturada e em desconformidade com preceitos constitucionais. Esse debate é importante, na medida em que a reabilitação de detentos é uma ação relevante na busca da redução de índices de criminalidade. A partir disso, o estudo tem como objetivo analisar a importância da reestruturação do sistema prisional brasileiro, como objetivos específicos: analisar o atual panorama do sistema carcerário brasileiro, entender a função social e punitiva das prisões, analisar as consequências positivas dessa ideia de reformulação.

O estudo se justifica a partir da ideia de que o sistema prisional brasileiro se encontra completamente desestruturado, não cumprindo suas funções em conformidade com preceitos 
centrais da Constituição, como da dignidade e dos direitos humanos, além do Estado não garantir estratégias eficazes em relação a reabilitação dos detentos, visando mitigar os índices de reincidência criminal. Para alcançar os objetivos propostos, a pesquisa é fundamentada por meio de uma revisão de literatura, com caráter qualitativo, em pesquisas relacionadas à segurança pública, de entendimento das funções do sistema prisional, e de possíveis estratégias para resolver os diversos problemas observados nesse ambiente.

Com esses pressupostos de pesquisa estabelecidos, o estudo está estruturado do seguinte modo: inicialmente são trazidos alguns importantes conceitos e panorama do sistema prisional brasileiro, trazendo um contexto histórico de suas funções punitivas e sociais, depois, é discutido o atual cenário da segurança pública no Brasil, fomentando a importância de estratégias variadas para a efetivação de direitos constitucionais dentro das unidades penitenciárias.

\section{SISTEMA PRISIONAL BRASILEIRO}

Antes mesmo de abordar conceitos específicos acerca do atual panorama das unidades 1009 penitenciárias no Brasil, é importante trazer uma reflexão a respeito do conceito de pena, que embora tenha estipulações específicas dentro do ordenamento jurídico brasileiro, já teve ao longo da história diversas características. De acordo com Melo (2016) o conceito foi se modificando ao longo do tempo e das civilizações.

O primeira legislação de direito que se tem conhecimento, trata-se do chamado "código de Hamurabi”, estas normativas da história antiga, tinham como característica central a reciprocidade em relação aos atos cometidos. Tomando precauções quanto ao anacronismo, cabe dizer que os transgressores da lei daquele período, que tinha suas características particulares, eram punidos de acordo com aquilo que haviam feito, não se havia preocupação com a reabilitação e sim, com a vingança. Essa vingança inclusive poderia se expandir para os demais membros da família do transgressor, tornando a punição até mais severa que o próprio ato ilegal 
para o período, praticado (ALVARENGA, 2017). Acerca do código de Hamurabi, cabe trazer algumas reflexões:

O Código de Hamurabi é considerado o símbolo da civilização mesopotâmica e um dos documentos mais importantes da História do Direito. Admirado pelos historiadores devido ao seu conteúdo jurídico, o Código de Hamurabi é também uma fonte de informações sobre sociedade, religião e economia da Babilônia nesse período histórico A importância histórica do Código de Hamurabi pode ser avaliada pelo fato de ele ter se tornado a fonte jurídica na qual se basearam as leis de praticamente todos os povos semitas da Antiguidade, incluindo os assírios, os caldeus e os próprios hebreus (ALVARENGA, 2017, p.6)

Como citado, a forma de punição nesse período se caracterizava pela reciprocidade dos atos. Embora esses conceitos não sejam os adotados na sociedade contemporânea, trouxeram diversas influências. Mas antes mesmo da ideia de punição pública, que é a utilizada como parâmetro no Brasil atualmente, também houve o período onde a punição era diretamente atrelado a religião e a igreja (BAQUERO, 20II)

Esse período de punição religiosa, precisa ser entendido como a época onde o próprio Estado e a religião agiam de forma conjunta, com influências múltiplas, onde os transgressores poderiam ser punidos pelo Estado, mas com uma penitencia diretamente atrelada a religiã $\mathbf{p}_{010}$ Dando um salto histórico, chegamos ao atual contexto de pena como a privação de liberdade, mas respeitando determinados preceitos (BAQUERO, 20II)

Com a inserção a partir do inicío do século XX, de ideias relacionadas aos direitos humanos e o direito de preservação de dignidade de todos os cidadãos, ocorreu a ruptura de alguns aspectos acerca do conceito de pena, sendo que a própria Constituição Federal, promulgada em 1988, passou a contar com determinados preceitos, que garantem a todos a preservação dos seus direitos basilares, como forma de garantir a dignidade da pessoa humana, independentemente das suas condições sociais, econômicas, religiosas, entre outras (MACHADO, GUIMARÃES, 2014)

Como dito, as prisões no Brasil e a forma como ocorre a gestão das mesmas no Brasil, são decorrentes de um longo processo histórico. A Constituição brasileira, promulgada no ano 
de 1988, assegura uma série de direitos a todos os cidadãos, os chamados direitos fundamentais, que envolvem entre outras coisas, a liberdade de ir e vir. Acontece que no momento que alguém comete algum ato ilícito, é julgado e condenado, perde provisoriamente essa liberdade, sendo sua tutela passada ao Estado, que os insere em unidades prisionais. Ou seja, a punição por seus atos ocorre por meio da privação de liberdade, embora essa questão seja também assegurada pela legislação, outros direitos da população não devem ser suprimidos, como forma de garantir sua dignidade (MIRANDA, 2016)

Mas cabe enfatizar esses fatores, pois não é incomum que as penitenciárias brasileiras, sejam geridas com um pensamento adverso as suas reais funções, isso quer dizer que muitos locais que deveriam punir somente com a privação de liberdade, são locais altamente degradantes, ferindo completamente a dignidade e os direitos humanos, se caracterizando como ambientes sem adequadas condições sanitárias, de alimentação e atendimento médico. Muitos entram no sistema prisioanal, e são expostos a situações degradantes, configurando uma completa ausência do Estado em relação a estratégias de reabilitação e busca pela diminuição dos índices de criminalidade (MIRANDA, 2016)

O conceito de pena foi se modificando ao longo da história, se em outros momentos e civilizações, a punição tinha teor de reciprocidade, ou seja, de vingança, no contexto contemporâneo, a pena se tem caráter público, sendo o Estado o responsável por investigar, condenar e punir o infrator, estipulando sua condenação de acordo com a gravidade dos seus delitos (BAQUERO, 20II)

Mas como um estratégia de longo prazo, o sistema prisional não busca apenas privar da liberdade, mas também deve ser norteado por estratégias voltadas a reabilitação e futura reinserção em sociedade do detento:

O sistema prisional brasileiro tem como objetivo a ressocialização e a punição da criminalidade. Assim sendo, o Estado assume a responsabilidade de combater os 
crimes, isolando o criminoso da sociedade, através da prisão, o mesmo é privado da sua liberdade, deixando de ser um risco para a sociedade (MACHADO, GUIMARÃES, 2014, p.568)

Apesar de existir em âmbito legislativo determinações que enfatizam que o sistema carcerário não tem somente a função de punir através da privação de liberdade, mas que também deve assegurar meios para a reabilitação dos detentos, esse cenário não se efetiva na prática, pois a estrutura destes locais normalmente são altamente deficitárias (BAQUERO, 20II)

Muitos fatores podem contribuir para essa ausência de estrutura das unidades prisionais brasileiras. Um destes aspectos, é os discursos políticos e a opinião pública. É comum existirem correntes de opinião, tanto políticas quando da mídia, que enfatizam que as cadeias realmente devam ser complexos que tragam sofrimentos para a população carcerária, como uma forma de punir os detentos por seus atos ilícitos, esquecendo que a punição já é efetivada pela privação de liberdade (BAQUERO, 20II)

O fato de grande parte da população, assim como de determinadas correntes políticas apoiarem a ideia de que as unidades prisionais devam ser locais degradantes, fazem com que 9012 representantes públicos, não concentrem seus esforços de modo mais efetivo na resolução deste complexo cenário. Rocha (2016) afirma que estes fatores são determinantes para a ausência de medidas realmente efetivas por parte do poder público, onde muitos representantes públicos, até por medo de perca de popularidade, preferem centrar seus esforços em outras questões, ou até mesmo colocar os investimentos em segurança pública, voltados especificamente para tornar as ações policiais mais severas, partindo da premissa de que a repressão pode resolver ou minimizar os problemas da violência no país (BAQUERO, 20II)

Sendo assim, deve existir uma mudança também nas atitudes políticas e na mentalidade dos representes públicos, que precisam considerar as unidades prisionais como unidades não só de punição, mas também de reabilitação, e com isso empreender esforços para a melhoria das 
mesmas, pois o que se nota no contexto atual brasileiro, é a completa ausência de medidas eficazes para a resolução deste complexo problema.

\section{SISTEMA PRISIONAL E AS ESTRATÉGIAS PARA A REABILITAÇÃO}

Os sistemas prisionais são locais necessários e importantes para a efetivação do Direito. Isso se deve ao fato de que as regras estabelecidas pelo ordenamento jurídico, preveem punições para os transgressores, não somente como forma de fazer com que alguém sofra por ter rompido com as regras sociais, mas também para não colocar em risco outras pessoas, ou de trazer detrimentos ao patrimônio público ou privado (MELOCI, PAVARINI, 2016)

Sendo assim, as prisões têm uma função estabelecida a partir de dois enfoques centrais: a privação de liberdade dos infratores e a reabilitação dos detentos para futura reinserção em sociedade. Pensando nisso, é necessário estabelecer alguns importantes preceitos para a efetivação de estratégias realmente eficazes no combate a reincidência, estes fatores envolvem não somente a melhoria da estrutura física destes locais, tão marcada pela completa negligência

sanitária, superlotação e demais aspectos adversos, é importante também que sejam feitas ações 1013 de teor educativo, de auxílio médico, liberdade religiosa, e ensino de um ofício (MELOCI, PAVARINI, 2016)

Desta forma, cabe na sequência do estudo abordar de forma um pouco mais específica sobre cada um destes quesitos. Primeiramente, cabe refletir sobre a importância da educação dentro das penitenciárias:

\footnotetext{
A garantia de uma boa educação é uma forma de ressocializar as pessoas condenadas à prisão, pois ela possibilita que, ao retornar à sociedade após quitar sua dívida com a justiça, os ex-presidiários tenham outras opções que não o regresso à criminalidade. Além disso, ela diminui significativamente a ocorrência de rebeliões dentro dos presídios, promovendo atividades de interação e reflexão que oferecem melhores perspectivas acerca do futuro. A adesão dos presos a uma modalidade de educação é ainda uma forma de reduzir o tempo da pena cumprida e, por consequência, uma maneira de diminuir a superlotação dos presídios (VIEIRA, 2015, p.9)
} 
Uma pessoa inserida no âmbito prisional, pode ter seus aspectos emocionais e psicológicos amplamente abalados, a sensação de impotência e isolamento, podem ser barreiras para a reabilitação deste detento. Ocorre que nesse período de privação de liberdade, é importante que este indivíduo repense seus atos e planeje uma reconstrução da sua vida em sociedade, isto é importante não somente para esta pessoa em específico, mas também para a coletividade, que irá compartilhar o ambiente com uma pessoa reformada e que não pensa em voltar a cometer crimes (VIEIRA, 2015)

Uma ferramenta importante para a efetivação deste cenário, é dar aos detentos possibilidades de acesso a educação, seja no prosseguimento de estudos mais avançados, ou até mesmo daquilo que for mais básico, pois estes processos pedagógicos podem servir como elemento inicial para essa reformulação, mostrando ao detento que este pode ser inserido na sociedade novamente, e que suas ações não precisam estar ligadas a ilegalidade (VIEIRA, 20I5)

Outro aspecto importante para a reabilitação das pessoas inseridas no ambiente prisional, é o auxílio médico. Esta assistência de profissionais médicos é importante nẫo somente pelo aspecto físico, mas também emocional e psicológico. Um detento que receber apoio, terá maiores capacidades de lidar com esse momento difícil de privação de liberdade, e ter a consciência necesssária para não repetir seus atos ilícitos após regressar da cadeia. A prestação de auxílio médico para os detentos, é obrigação do Estado, que deve dar assistência para o tratamento de doenças, sejam estas psicológicas ou físicas, efetivar essas ações é uma obrigação constitucional (MELOCI, PAVARINI, 20I6)

Um exemplo prático da necessidade de prestação de assistência médica, é para os detentos dependentes químicos, especialmente de drogas. Isso é importante, pois usuários de drogas ao ingressarem no sistema prisional, terão que aprender a viver sem seu vício, mas isso ocorre de forma abrupta, podendo causar crises de abstinência e revolta. Obviamente, o Estado 
não deve permitir que os detentos façam uso de qualquer tipo de droga dentro das prisões, mas somente isso não basta, é preciso também que preste auxílio a estas pessoas, para que esse processo ocorra da forma correta do ponto de vista clínico. Receber essas atenções por parte do poder público, pode ser uma importante estratégia na busca da reabilitação destes detentos (TOMÉ, 2015)

Uma pessoa inserida no âmbito carcerário, precisa de motivação para seguir convicto do seu processo de mudança, pois a desestrutura destes locais torna esse cenário mais complexo. Justamente por isso, se destaca a importância de uma outra questão, que também é premissa constitucional: a liberdade religiosa (TOMÉ, 2015)

Independentemente da crença religiosa de determinado detento, esse pode ser im importante caminho na busca da reabilitação. As religiões tem como premissa a vida dentro dos preceitos morais, a partir da fé, é possível que estes detentos dirijam suas ações em prol de um bom convívio social, dentro dos limites da lei. Acerca da importância da liberdade religiosa dentro das unidades penitenciárias, é importante expor a seguinte reflexão:

Revela-se a religião como uma das formas de se viabilizar a ressocialização do ${ }^{0}$ delinquente. A esperança, principal marca da religião, é capaz de transformar a vida do detento, apontando-lhe outra opções de vida. A experiência religiosa pode ser um dos caminhos para a ocorrência da modificação interior do indivíduo. Por meio da aceitação do mundo sagrado as pessoas estariam voltando a si mesmas, aceitando-se e reconciliando-se com seus impulsos (TOMÉ, 2015, p.4)

Para a pesquisadora citada anteriormente, a religião se mostra como uma estratégia capaz de gerar esperança no detento para uma vida melhor após a saída da prisão, entendendo que caminhar dentro da legalidade é o caminho mais correto, do ponto de vista religioso e também pela ótica social (OLIVEIRA, 2017)

Outro importante fator para a busca de reabilitação da população carcerária, é utilizar o tempo da detenção para o aprendizado de um ofício. Privar uma pessoa de liberdade como forma de punição, se mostra a melhor forma de afastar um indivíduo perigoso da sociedade, mas a 
legislação brasileira não permite que ninguém fique mais do que 30 anos presa, independentemente do ato de infração que tenha praticado (OLIVEIRA, 2017)

Sendo assim, por mais que demore décadas, a pessoa presa irá retornar para a vida em sociedade, mas todo esse tempo que passou em reclusão, assim como o preconceito presente na sociedade contra essas pessoas, fazem o processo de readaptação da vida social uma tarefa complexa, ainda mais se levar em conta a questão do sustento dessa pessoa, que se não tiver o apoio de terceiros, terá dificuldades para se inserir no mercado de trabalho e de se sustentar. Esses fatores, fatalmente, fomentam um cenário de reincidência criminal (OLIVEIRA, 20I7)

Uma forma de minimizar a ocorrência de cenários análogos a este citado anteriormente, é incentivar o ensino de um ofício para os detentos. Sabendo que esse tipo de iniciativa pode trazer benefícios para outros setores também, como a partir da produção de produtos, por exemplo. A respeito da importância do trabalho dentro do ambiente prisional, é importante citar:

Na nova concepção penitenciaria, a pena tem a finalidade, no momento da execução, reabilitadora ou de reinserção social. O trabalho nas prisões é entendido hoje com 1016 sendo a atividade dos presos e internados, no estabelecimento penal ou fora dele, com remuneração. O labor prisional não constitui uma agravação da pena, nem deve ser doloroso e mortificante, mas um mecanismo de complemento do processo de ressocialização, prepara-lo para uma profissão, inculcar-lhe hábitos de trabalho e evitar a ociosidade. Exalta-se seu papel de fator ressocializador (OLIVEIRA, 2017, p.48)

Cabe salientar que o trabalho dentro das prisões, assim como o processo de ensinar o ofício para alguém, não deve ser feito de modo doloroso. Ou seja, o trabalho não deve ter caráter compulsório, e sim, como uma opção para cada detento, mas sempre deixando claro aos mesmos, a importância desse tipo de ação, que poder inclusive gerar renda para sus famílias e servir como uma importante ferramenta para sua futura reinserção na sociedade (ALVARENGA, 2017) 
A partir da exposição de todas essas possíveis estratégias para a reabilitação e futura reabilitação da população carcerária, cabe enfatizar que as ações nesse sentido precisam ter caráter amplo, e ser pensadas a médio e longo prazo. O Estado precisa manter essas ações de forma contínua, onde a reabilitação e a busca pela diminuição dos índices de violência e de reincidência criminal sejam cada vez menores.

\section{${ }_{4}$ CONSIDERAÇÕES FINAIS}

A partir da presente revisão de literatura, foi possível entender alguns importantes fatores relacionados ao sistema penitenciário brasileiro. Inicialmente, o estudo abordou as atuais características das cadeias nacionais, para isso, trouxe também um contexto histórico acerca do conceito de pena. Se na antiguidade, a pena por um ato de infração estava centrada na vingança e na reciprocidade, como no código de Hamurabi, isso foi se modificando ao longo dos séculos, passando pela fase da vingança religiosa, até chegar as atuais características de privação de liberdade como forma de punir, a partir da tutela do Estado.

Explicado estes fatores basilares, o estudo se concentrou na análise do tratamento do poder público em relação as cadeias, e ficou exposto que diversos fatores podem trazêp17 consequências negativas para a melhoria destes ambientes, inclusive a própria opinião pública, que não se mostra em grande medida, favorável a medidas de reestruturação das unidades penitenciárias, entendendo que estes ambientes realmente devem expor os detentos a situações degradantes, como forma de punição pelo atos cometidos em quanto estavam em liberdade.

Esses discursos também são reforçados por representantes políticos, que colocam a proteção dos direitos humanos, assim como a melhoria e reestruturação das penitenciárias como algo secundário, e voltado especificamente a atender as demandas de pessoas que vivem à margem da sociedade. Contudo, o estudo mostrou que essa abordagem é rasa, que não contempla as necessidades sociais e de segurança pública, além de ser uma afronta a preceitos constitucionais. Pensando nisso, se mostrou evidente a necessidade de estratégias bem delineadas para a utilização dos espaços penitenciários não somente como ferramentas para a 
punição, mas também como locais capazes de promover a reabilitação e futura reinserção destes detentos na sociedade.

A primeira estratégia salientada no estudo, foi a promoção de ações educativas dentro das prisões, desde o nível básico ao mais avançado, para que através dos processos de ensino e aprendizagem o detento perceba suas potencialidades, e que não volte a cometer crimes após deixar a prisão.

O segundo aspecto, é a assistência médica. Embora seja um preceito constitucional e assegurado a todos os cidadãos, as cadeias se mostram locais decadentes nesse sentido, onde não há o devido acompanhamento médico dos detentos, principalmente das doenças psicológicas. Pessoas inseridas dentro dos espaços prisionais, tendem a serem acometidos por doenças como depressão, abstinência, entre outras, e sem o devido tratamento os quadros podem se agravar e dificultar qualquer processo de reabilitação destes detentos.

Outro ponto importante na busca pela reformulação dos espaços prisionais, é a liberdade religiosa. Por meio da fé, muitos podem pacificar suas angústias, criar esperanças para uma vida futura dentro da lei, percebendo que esse tempo detido, deve servir como um momento de18 aprendizado, e não um motivo para se revoltar ainda mais e voltar a cometer crimes no futuro. Por fim, foi debatido o ensino de ofícios e o trabalho como uma estratégia igualmente relevante.

Através do trabalho e do ensino de ofícios, o detento pode combater os detrimentos trazidos pela ociosidade, além de projetar um futuro após sua libertação. Um dos grandes desafios dos ex-detentos, é se inserirem novamente no mercado de trabalho após o cumprimento de sua pena, a partir do momento em que este aprende um ofício, essa tarefa se torna menos complicada.

A partir da exposição destes fatores, é possível enfatizar que os objetivos da pesquisa foram alcançados, havendo a explanação de importantes fatores, assim como discutindo possíveis estratégias relevantes e em conformidade com a Constituição, mitigando 
gradativamente os problemas de segurança pública, diretamente relacionados ao sistema penitenciário.

\section{REFERÊNCIAS}

ALVARENGA, Lennys Francis de. A importância histórica e as principais características dos códigos de Hamurabi e de Manu. Revista jurídica eletrônica/Ano 6, Número 8, fevereiro/2017 Universidade de Rio Verde

BAQUERO, Marcelo. Democracia formal, cultura política informal e capital social no Brasil. Opin. Publica vol.r4 no.2 Campinas Nov. 2oII

MACHADO, Nicaela Olímpia; GUIMARÃES, Issac Sabbá. A Realidade do Sistema Prisional Brasileiro e o Princípio da Dignidade da Pessoa Humana. Revista Eletrônica de Iniciação Científica. Itajaí, Centro de Ciências Sociais e Jurídicas da UNIVALI. v. 5, n.I, p. 566-581

MELOSSI, D. E PAVARINI, M. Cárcere e fábrica: As origens do sistema penitenciário (séculos XVI-XIX). Rio de Janeiro: Revan, 2006.

MIRANDA, Angélica Fernandes. Questões sobre a população prisional no Brasil: Saúde, Justiça e Direitos Humanos. Editora Proex, 2ª edição, Vitória, 2016

OLIVEIRA, Adriana Bezerra Caminha de. O Trabalho como Forma de Ressocialização do Presidiário. [Mestrado] Universidade Federal do Ceará, 2017.

ROCHA, Alexandra Pereira da. O Estado e o direito de punir. Rio de Janeiro. Ed. Zahar, 2016

TOMÉ, Fernanda Terezinha. A influência da religião na ressocialização de detentos no presídio regional de Santa Maria - RS. ıoa Edição. Santa Maria, Junta de Educação Religiosa e Publicações, 2015 